\title{
Formas de produzir saúde no trabalho hospitalar: uma intervenção em psicologia
}

\author{
Maristela Dalbello de Araujo ${ }^{1}$, \\ Elaine Araujo Busnardo, Flávia Moreira Marchiori, \\ Milena Fiorim de Lima e Tatiane Mattos Endlich ${ }^{2}$
}

\begin{abstract}
Trata de uma intervenção desenvolvida em um hospital público da Grande Vitória, Espírito Santo. A intervenção teve como objetivo conhecer a realidade de trabalho e as repercussões para a saúde dos profissionais que desenvolviam suas atividades no setor de pediatria, visando, em última instância, produzir um espaço de reflexão e crítica que pudesse funcionar como dispositivo de mudança, tanto das condições de trabalho tidas como causadores de sofrimento, como das relações entre os participantes da equipe de enfermagem. Utilizou o método dos encontros coletivos, nos quais foram abordados diversos temas acerca da realidade de trabalho e das possíveis conseqüencias para a saúde e para a vida desses homens e mulheres. Constata que as condições e a organização do trabalho daquele hospital têm favorecido o adoecimento, devido a um processo de desqualificação e precarização do serviço público. Conclui que a intervenção realizada possibilitou que surgissem algumas atitudes de enfrentamento e busca de soluções coletivas. No entanto, ressalta que ainda há muito a ser feito para abrir espaços coletivos, como o relatado, que possibilitem a co-gestão do trabalho e que se destinem a produzir saídas para os inúmeros problemas que abrigam o cotidiano do trabalho hospitalar.
\end{abstract}

Palavras chaves: trabalho hospitalar, psicologia do trabalho, saúde e trabalho, intervenção em psicologia.

\section{Introdução}

$\mathrm{O}$ projeto de extensão Trabalho Ë Saúde vem sendo desenvolvido, desde 1997, com o objetivo de refletir com os trabalhadores de diferentes categorias sobre as implicações do trabalho para suas vidas e particularmente para a saúde.

Durante o ano de 2000, foi desenvolvido um subprojeto juntamente com os funcionários do setor de pediatria de um hospital público da Grande Vitória, Espírito Santo.

Algumas questões estiveram presentes desde o início dessa intervenção: por que um lugar que deveria promover a saúde acabava produzindo adoecimento? Quais fatores da organização do trabalho desse hospital levam ao adoecimento de seus funcionários? Quais mudanças devem ser produzidas para a construção de uma vida mais saudável nesse local de trabalho?

As discussões apontaram um expressivo desgaste físico, mas, principalmente, um sofrimento psíquico agravado pela impossibilidade de falar sobre tal sofrimento, o que levava cada um a vivê-lo de maneira solitária, responsabilizando-se de forma individual pela sua

\footnotetext{
${ }^{1}$ Professora adjunta do Departamento de Psicologia da Universidade Federal do Espírito Santo, coordenadora do projeto de Extensão Trabalho $\mathcal{E}$ Saúde.

${ }^{2}$ Alunas do curso de Graduação em Psicologia da Universidade Federal do Espírito Santo.
} 
causa. No entanto, pudemos perceber que a oportunidade de compartilhar esse desconforto e sofrimento possibilitou a construção de atitudes de enfrentamento diante dos problemas apresentados e, consequentemente, a melhoria do ambiente de trabalho e da própria saúde.

\section{Trabalho e saúde}

Elegemos o trabalho como aspecto central para a análise do homem. Isso porque consideramos que o homem se tornou humano através de sua ação sobre a natureza, das trocas entre si e pelo seu trabalho. Por meio de um movimento dialético, à medida que modificava o ambiente, modificava-se também a si próprio (Rigotto, 1994). Esse movimento que se verifica até hoje, visto que o homem está em constante mudança, adquirindo novos conhecimentos e habilidades ao modificar o ambiente que o cerca e ao estabelecer relações sociais nesse processo.

Entendemos, contudo, que essa atividade humana sobre a natureza não se deu sempre da mesma forma e que determinadas condições históricas, políticas e econômicas favoreceram a emergência do trabalho com características e significados diferentes a cada tempo dado.

Assim, como assinala Braverman (1981), o desenvolvimento da industrialização, sob a égide do capitalismo, operou modificações no trabalho humano que comprometem o projeto de hominização intrínseco a essa atividade social. E, em nossos dias, o trabalho tem resultado freqüentemente em sofrimento e dor.

A partir disso, podemos problematizar o significado que a atividade trabalho representa para cada grupo de trabalhadores e contribuir na produção de outros significados para essa atividade. Significados que sejam constextualidados historicamente e mais condizentes com a realidade daquele grupo, respondendo às suas necessidades. Esse tem sido o nosso desafio, já que a forma como o trabalho está organizado em nossa sociedade tem levado o homem a se submeter a determinadas condições de sofrimento físico e mental que contribuem para o seu adoecimento.

\section{Como afirma Rigotto (1994):}

O trabalho no Brasil nos últimos quinze anos levou pelo menos 60.000 pessoas à morte $\mathrm{e}$ 300.000 a mutilações incapacitantes. O "progresso" gerado nos últimos 60 anos de industrialização não resolveu os problemas básicos que levam às "doenças da miséria" e ainda levou à elevação das doenças crônico-degenerativas, cardiovasculares, profissionais, mentais e do câncer (p. 27).

Além disso, o trabalho tem duplo caráter: se, por um lado, é dispêndio de força motriz, desgaste, consumo de energia, por outro, o trabalho humano é intencional, tem produção de conteúdo significativo para quem o exerce. Dessa maneira, a atividade ganha sentido se o ser humano consegue se reconhecer no conteúdo da tarefa que realiza e no produto final do seu trabalho.

Quando essa ação está sendo benéfica para o desenvolvimento das potencialidades e habilidades criadoras do homem, de modo que este consiga produzir significados por meio do que faz, o trabalho pode ser produtor de saúde. Mas, ao contrário, se não desenvolve a criatividade humana e se apropria de certas habilidades, desconsiderando e atrofiando outras que poderiam ser efetivadas provoca adoecimento. Dejours, Dessors e Desriaux (1993) afirmam que: 
O trabalho não é somente um modo de ganhar a vida - é também uma forma de inserção social onde os aspectos psíquicos e físicos estão fortemente implicados. $\mathrm{O}$ trabalho pode ser um fator de deterioração, de envelhecimento e de doenças graves, mas pode também se constituir em um fator de equilíbrio e de desenvolvimento. A possibilidade da segunda hipótese está vinculada a um trabalho que permita a cada indivíduo aliar as necessidades físicas ao desejo de executar a tarefa (p. 98).

Outro ponto importante para a compreensão dessas vivências diz respeito ao sentido e à concepção do que é entendido como saúde. A palavra saúde é marcada por uma pluralidade de leituras e concepções possíveis, advindo daí a sua multiplicidade de sentidos em cada campo de conhecimento. Segundo Birman (1999):

A inserção das ciências sociais e humanas no campo da saúde pública teve o mérito incalculável de criticar a hegemonia incontestável do paradigma biológico e naturalista, propondo a existência de outros paradigmas na interpretação das experiências fundamentais da saúde coletiva. E, nesse sentido, a saúde coletiva teve o impacto de relativizar a leitura biológica e naturalista da palavra saúde, pela valorização de outras dimensões e contextos do real advindos dos discursos da sociologia, da antropologia social, da psicanálise, da história e da filosofia. (...) Logo, a palavra saúde é marcada pela complexidade (p. 7).

Neste artigo utilizamos o conceito de saúde baseado principalmente nas idéias do filósofo e médico Georges Canguilhem (1978). Para ele, promover a saúde não é buscar o equilíbrio e o bem-estar, mas dar condições de escolha e criação aos indivíduos. Isso porque, segundo seu ponto de vista, saúde diz respeito à possibilidade de o corpo realizar o que, em princípio, parecia impossível, daí a idéia de transgressão ao imposto. Essa idéia concerne não apenas aos atletas, que sempre procuram superar-se, mas também ao mais comum dos homens que busca transformar e corrigir um meio social que lhe é adverso, de maneira que seu corpo encontre uma forma de estar que lhe seja saudável (Caponi, 1997, p. 298). Ou seja, a saúde, nesse contexto, implica uma meta, objetivos a serem atingidos, um projeto, individual e coletivo, dinâmico e mutante como a própria vida.

Nesse sentido, para ter saúde, é preciso liberdade: liberdade para regular as variações que aparecem no estado do organismo; liberdade de poder dormir quando se tem sono, de poder comer quando se tem fome, de beber quando se tem sede (Dejours, 1986). Podemos, então, falar de saúde como uma forma diferenciada e específica para cada sujeito, que tenta se adequar às variações com as quais tem que conviver. Saúde é a própria luta pela vida, é ter metas e objetivos com perspectivas de alcance, mesmo que estejam obscurecidos pela realidade, mesmo que sejam utópicos. É ter esperança e buscar meios para consegui-la. Falar em saúde é apontar a capacidade de quebrar regras dadas que nos causam mal-estar. É também ter condições de criar novas regras, de acordo com os nossos interesses, saindo da passividade de aceitar os fatalismos e construindo estratégias para mudar o ambiente que nos rodeia.

Assim, a ausência de saúde não seria apenas a doença, nem um agravo capaz de causar a morte, mas tudo o que causa um certo sofrimento inaceitável em vida, qualquer forma de "morte-em-vida".

\footnotetext{
${ }^{3}$ Referência ao termo utilizado por João Cabral de Mello Neto em sua obra Morte e Vida Severina, de 1956. Esse termo significa uma forma de vida em que já não se pode ter alegrias, motivações, desejos ou quaisquer perspectivas de melhora. A "morte-emvida" ou "vida severina" refere-se a um estado que não se pode chamar de vida, pois não mais se vive, apenas se sobrevive.
} 


\section{Os trabalhadores do hospital}

Em diferentes épocas a sociedade tem se preocupado com os doentes e, de alguma forma, tem buscado meios para deles cuidar. As primeiras instituições que surgiram com essa finalidade foram os conventos e os mosteiros, que se ocupavam principalmente da vida espiritual e estavam mais apreensivos com a salvação da alma do enfermo (Foucault, 1979).

Desde a Idade Média, havia mulheres que cuidavam de doentes, idosos, crianças, deficientes, pobres e de outras mulheres. Seus conhecimentos eram passados de mãe para filha, de geração em geração. Para o povo, eram mulheres sábias e com enorme poder de cura e resolução. Essas mulheres desenvolveram grandes conhecimentos ligados aos ossos e músculos, ervas e drogas. No entanto, durante os anos de Inquisição, foram perseguidas pelas autoridades e pela Igreja, que as consideravam como feiticeiras ou charlatãs. Os registros da época indicam a existência de mulheres pobres e leigas que viviam nos hospitais cuidando de doentes, sem qualificação específica, e assinalam também que as condições de vida nesses locais eram quase intoleráveis: sujeira, abandono e doenças se misturavam por toda a parte (Lima, 1993).

Posteriormente, esse papel do cuidado com o outro foi sendo assumido pelas congregações cristãs e, mais tarde, quando tecnificado e medicalizado, foi passado para os técnicos e especialistas (Lima, 1993).

A enfermagem foi se constituindo historicamente como uma profissão exercida majoritariamente por mulheres, realizando, no espaço público, atividades semelhantes àquelas que elas comumente exerciam na esfera do mundo privado, tais como: alimentar, lavar, limpar, etc. Habita o imaginário erudito e popular da cultura patriarcal a idéia de que existe uma associação entre ocupação e gênero que liga a sexualidade biológica com algumas atividades humanas. Essa associação é significativa, pois o fato da enfermagem ser vista socialmente como uma profissão feminina, tem implicado menor prestígio profissional para quem a exerce, ou seja, menores salários, representações de uma atividade pouco qualificada, que apenas ajuda as atividades principais. Isso se apoia na idéia socialmente construída de que se trata de uma atividade "naturalmente" fácil de realizar para as mulheres que as exercem.

Segundo Vieira e Araujo (2003, p. 17), há uma naturalização das competências femininas. Ou seja, todo o trabalho relacionado ao mundo privado, doméstico, de cuidar da casa, educar os filhos e, inclusive, as tarefas de limpeza, foi sendo considerado como decorrente das qualidades das mulheres e não como qualificações.

As diferenças entre os profissionais de saúde são claras nos seus aspectos técnicos, sociais e políticos. Essa associação de gênero somada a uma relação histórica de abnegação e inferioridade se reproduz hoje na relação da enfermagem com outros profissionais de saúde, na desigualdade de seus salários, na mecanização de suas tarefas e na desqualificação da profissão, tanto por outras áreas, quanto por eles próprios, que, incorporando esse estereótipo, não lutam por um reconhecimento adequado, por melhores salários e por melhores condições de trabalho (Lima, 1993).

No Brasil, até o início do século XX, a enfermagem era praticada por religiosas, cujo paradigma enfatizava o amor, a abnegação e o desprendimento, não valorizando a luta por remuneração digna, condições adequadas de trabalho e inserção na vida social e política (Lima, 1993).

Esse paradigma deixou fortes marcas que se mostram até os dias de hoje. Parece predominar, ao menos nas equipes de enfermagem com as quais trabalhamos, um ideário de que nada pode ser feito para melhorar as suas condições de trabalho. 


\section{Nossa intervenção: objetivos e metodologia}

O nosso objetivo foi refletir, junto com os trabalhadores da saúde de um hospital público da Grande Vitória, sobre os impactos do trabalho hospitalar na produção de sua própria saúde/doença. Essa reflexão, visando à busca de soluções compartilhadas para os problemas do cotidiano de trabalho no setor de pediatria daquele hospital, foi a resposta possível ao pedido feito, pela chefia, ao Núcleo de Psicologia Aplicada da Universidade Federal do Espírito Santo. Nesse pedido, solicitava uma intervenção em psicologia que promovesse um melhor clima para o desenvolvimento do trabalho e pudesse "tratar dos conflitos interpessoais ali presentes".

Utilizamos o método dos encontros coletivos como espaço de diálogo e reflexão sobre as condições $d$ trabalho e sobre as responsabilidades de cada um na manutenção ou mudança da situação de trabalho. Baseamo-nos nas proposições metodológicas da Psicodinâmica do Trabalho, que evidencia a importância do grupo em detrimento das investigações individuais, que tendem a remeter os sofrimentos gerados pelo trabalho (condições e organização) às características de personalidade moldadas nas histórias individuais.

Dejours e Abdoucheli (1994, p. 124) afirmam que “...os trabalhadores em grupo eram capazes de reconstruir a lógica das pressões de trabalho que os fazem sofrer e também podiam fazer aparecer estratégias defensivas coletivamente construídas para lutar contra os efeitos desestabilizadores e patogênicos do trabalho".

Também buscamos colher dados por meio da observação do ambiente de trabalho e das relações que os trabalhadores estabelecem entre si e com esse espaço. Muitos acontecimentos perpassam esse ambiente sem que os trabalhadores tenham uma percepção objetiva sobre eles, não conseguindo transmiti-los em forma de discurso. Nesse sentido, os registros dessas observações foram postos em análise a cada encontro coletivo e assim nossas observações puderam ser analisadas e discutidas por eles de maneira a desnaturalizar alguns procedimentos e idéias arraigados naquele espaço de trabalho e convivência. As observações também foram úteis para nos preparar para a tarefa, familiarizando-nos com termos, aparelhos e procedimentos que se tornaram temas recorrentes durante os encontros.

Dessa forma, procurávamos identificar alguns fatores que escapavam ao olhar dos trabalhadores em questão e que, de certa forma, estavam influenciando sua saúde. Esses fatores eram trazidos para o debate e esmiuçados, só então eram validados ou descartados como fontes de sofrimento.

\section{Enfermaria de pediatria do hospital}

O hospital em questão foi fundado com o objetivo de dar suporte à formação dos alunos dos cursos de Biomédica de uma universidade, além, é claro, de proporcionar o atendimento público às mais diversas demandas de saúde da população. É procurado por pessoas de todas as classes sociais, principalmente aquelas que não dispõem de planos de saúde. Entretanto, por ser um hospital universitário, tem também o compromisso de desenvolver pesquisas e tecnologia em saúde.

Durante os últimos anos, esse hospital-escola vem sofrendo com o descaso por parte do Estado, seu mantenedor, e isso fez com que, naquele momento, os funcionários apontassem inúmeros problemas: falta de verbas, de pessoal, de condições mínimas de atendimento, de salários compatíveis com a realidade econômica, de equipamentos, 
instalações adequadas e sobretudo, falta de reconhecimento profissional.

Essas faltas vêm produzindo um senso comum de ineficácia do setor público, que associa o trabalhador público a uma imagem de negligência e ociosidade, o que não corresponde à realidade de muitos lugares. É claro que existem instituições públicas que aplicam mal o dinheiro dos impostos. No entanto, há outros espaços que vêm produzindo diversos avanços, mesmo com tantas limitações de reconhecimento, incentivo e verbas. Nesses espaços têm predominado a sobrecarga de trabalho, a pressão (da chefia e do público), os baixos salários e a desqualificação profissional. Muitos ainda lutam para exercer sua atividade da melhor forma possível, procurando vencer os muitos obstáculos e produzir outras imagens, diferentes dessa já cristalizada, que vê o trabalhador do setor público como ineficiente.

O setor de pediatria daquele hospital, durante o período em que lá estivemos, era composto pelos seguintes profissionais: três médicos, duas enfermeiras, vinte e oito técnicos e auxiliares de enfermagem, uma assistente social, uma estagiária de enfermagem e cerca de dez acadêmicos de medicina que realizavam a residência semestral no setor.

O trabalho dos funcionários é dividido por escalas que se alternam em seis plantões diferentes. Cada auxiliar/técnico de enfermagem trabalha 12 horas, no esquema de 12 horas de trabalho por 36 horas de descanso.

A nossa intervenção se iniciou com visitas ao setor e breves conversas com as pessoas que por ali circulavam. Nosso objetivo era conhecer o serviço, o ambiente, entender as tarefas e as principais dificuldades dos profissionais da enfermagem. Procurávamos perceber, também, o que havia de agradável no hospital, o que fazia com que muitas pessoas gostassem de trabalhar naquele local.

Negociamos com as chefias o melhor horário para uma reunião de abertura do projeto, na qual explicaríamos nossos objetivos, definiríamos locais, datas e horários e faríamos as inscrições dos interessados.

Tivemos várias dificuldades para encontrar horários em comum, devido às escalas incompatíveis, a outro emprego e às dificuldades com transporte ${ }^{4}$. Realizamos, então, seis reuniões, uma em cada plantão. Assim, estando presente no horário de trabalho, conseguimos conversar com todos os funcionários. Nessas reuniões, os trabalhadores demonstraram empolgação e interesse pelo projeto, o que possibilitou a montagem de um calendário de reuniões e um cronograma de atividades.

Foram dezesseis horas de atividades grupais, distribuídas em quatro encontros, entre os meses de setembro e dezembro. Nesses encontros discutimos temas como: o trabalho em equipe, a relação com os colegas e a chefia; a importância do diálogo; a responsabilidade do grupo em buscar soluções para os problemas de seu cotidiano de trabalho.

Nessas reuniões utilizamos instrumentos e métodos variados: jogos, brincadeiras, textos, dinâmicas de grupo, músicas ou pequenas histórias. Começávamos com um tema genérico e os próprios participantes o direcionavam para um foco que discutíamos com maior ênfase. Ao final da reunião traçávamos metas e atividades visando melhorar, encaminhar ou resolver as questões discutidas. Esses assuntos eram retomados na reunião posterior para que sua discussão tivesse continuidade.

Alguns temas, por sua recorrência ou intensidade, tornaram-se analisadores desse cotidiano de trabalho, dentre eles:

\footnotetext{
${ }^{4}$ Muitos moravam em bairros distantes do hospital e outros cumpriam dupla jornada, trabalhando em outros hospitais e isso inviabilizava que os encontros fossem feitos fora do horário da escala.
} 


\section{O contato diário com a dor e a morte}

Lidar diariamente com pacientes que sofrem, vivenciar o contato com a dor de outro ser humano e encarar a morte de um paciente transtorna os trabalhadores dos hospitais. Segundo Pitta (1999), assumir o cuidado de pessoas doentes suscita diversos sentimentos e ansiedades contraditórias: piedade, compaixão, amor, culpa, ódio e ressentimento. Esse contato constante com pessoas fisicamente lesadas ou doentes impõe um fluxo de atividades agradáveis ou repulsivas e exige a adequação cotidiana para a qual muitos lançam mão de estratégias defensivas ${ }^{5}$ para o desempenho das tarefas.

Pudemos discutir esse tema, quase um tabu para o grupo, e perceber que há um misto de sentimentos em torno do assunto, normalmente associados à impotência dos funcionários em frente ao inexorável, o que acaba por produzir um sentimento de incapacidade geral. De toda forma, explicitou-se que se defender, afirmando que nada os afeta, não é o melhor caminho para lidar com essa situação, ao passo que compartilhar sentimentos contraditórios pode ser uma via para um enfrentamento mais saudável.

\section{Inexistência do sentimento de equipe}

Os funcionários daquele setor do hospital estavam reunidos para realizar suas tarefas, mas esse conjunto de pessoas não se apresentava como uma equipe que tem o mesmo objetivo. Ao perguntarmos qual era o objetivo final do trabalho de cada um, tivemos como resposta "o bom atendimento à criança e ao acompanhante", "fazer de tudo para que a criança retorne bem para casa". No entanto, esse objetivo não unia os que ali trabalhavam, uma vez que ficou evidente que condutas eram tomadas sem que fossem levados em conta os diferentes saberes e olhares entre as especialidades, de maneira a encontrar o melhor caminho a ser seguido para o restabelecimento da saúde da criança.

As decisões sobre medicação, visita médica, prescrição, diagnóstico e alta eram tomadas separadamente pelas especialidades. Assim, enquanto o médico e o grupo de acadêmicos realizavam a visita, a equipe de enfermagem estava ocupada em outra função ou cuidando de outro paciente, de modo que não era possível compartilhar e acompanhar a discussão sobre a enfermidade da criança internada.

A equipe enfermagem raramente era consultada para incluir suas observações cotidianas sobre a evolução dos pacientes. Isso resultou em uma queixa de que, muitas vezes, o saber dessa categoria não era valorizado. Algumas falas explicitavam a relação desta com os médicos e acadêmicos:

\section{Já aconteceu aqui de um acadêmico dar a alta para a criança e falar isso só para a mãe sem ao} menos consultar a gente para saber como estava aquele caso.

Situações como a mencionada acima apontam uma problemática bastante presente em equipes de trabalho nos hospitais. As atitudes tomadas, na maioria das vezes, não denotam respeito à diferença de funções, mas sim uma desqualificação e não reconhecimento do trabalho da enfermagem e de sua importância no cuidado e recuperação do paciente.

Em relação aos acadêmicos, que cumpriam a carga horária de formação nesse setor, a

\footnotetext{
${ }^{5}$ Chamamos de estratégias defensivas certas atitudes de negação e de desprezo pelas más condições de trabalho adotadas por muitos trabalhadores. Essas estratégias de neutralização da angústia e da revolta, segundo Dejours (1987), são extremamente necessárias, sob o risco de os trabalhadores não poderem mais realizar as suas tarefas. Não se trata de inconsciência ou alienação. O desprezo, a ignorância e a inconsciência são apenas uma fachada, cuja eficácia simbólica ajuda a superar os principais fatores de adoecimento físico e psíquico. (Dejours, 1987).
} 
reclamação se mostrou bastante pertinente, pois eles desconheciam a rotina, o que prejudicava todo o serviço da enfermagem, que dependia das prescrições e informações médicas, conforme exemplificam as falas a seguir:

Às vezes eles mudam a medicação e só nos avisam depois do horário quando já foi aplicada a medicação anterior.

Eles têm alta rotatividade aqui na pediatria. Quando chegam aqui não recebem orientação de como funciona o nosso trabalho. Eles chegam e saem sem dar um bom dia. Fazem um trabalho totalmente separado do nosso.

\title{
Falta de união na própria equipe de enfermagem
}

Existia ainda um outro fator que o grupo apontou como um agravante das condições de trabalho: a desunião dentro da equipe de enfermagem. Eles reclamavam do fato de que muitos não abriam mão de seus interesses pessoais para facilitar o trabalho do colega, no que se refere à carga horária de trabalho e à tarefa do cuidar. Assim se manifestaram alguns profissionais da enfermagem:

Tem hora que você precisa de ajuda na sua enfermaria e o outro finge que nem vê.

\begin{abstract}
É freqüente na última hora o funcionário escalado para aquele dia aparecer com um atestado de saúde na última hora e eu ter que ligar com urgência para alguém vir cobrir o serviço. Isso é muito estressante, eu sei que o atestado é falso.
\end{abstract}

\section{O cuidar de crianças}

Pelo fato de trabalharem com crianças, o grupo de enfermagem se queixava de ter maior responsabilidade, como se a atividade do cuidado, quando desenvolvida com crianças, pesasse mais, como se a vida das crianças tivesse um valor maior do que a dos adultos. Isso muitas vezes era justificado pelo fato de a criança ser totalmente frágil, à mercê dos cuidados dos adultos e por ela não compreender a necessidade da hospitalização. Além disso havia também dificuldades advindas do difícil relacionamento com os acompanhantes.

Para as crianças hospitalizadas, o entorno traz uma sensação de estranhamento e desconhecimento: as escalas, as enfermarias, os medicamentos, as funções, as profissões, a comida em bandejas, a falta da família e dos amiguinhos. Havia, por parte delas um profundo desconhecimento do ato médico, cujo sentido associam com intenções punitivas e castigos. Enfim, para elas o hospital representa comumente um lugar de proibições onde é proibido gritar, correr, jogar bola. É também um local de infantilização, pois os adolescentes e as crianças são tratados sem diferenciação.

\section{A presença dos acompanhantes}

A presença dos acompanhantes agravava ainda mais a tensão interna no setor. Os parentes nutrem sentimentos contraditórios em relação ao hospital e expressam particularmente e mais diretamente às enfermeiras, o que, com freqüência, as deixavam confusas e angustiadas. Alguns acompanhantes demonstravam preocupação, apreço, gratidão, respeito e crença no funcionamento do hospital; outros, ao contrário, desqualificavam as ações da enfermagem, não seguiam suas orientações, discutiam, tornavam-se ausentes e negligentes e até criavam impasses. Alguns eram muito exigentes e críticos e até mesmo possessivos em relação às suas crianças; outros pareciam nem se 
importar e abandonavam o filho à disciplina e à solidão do hospital. Todos esses fatores faziam da presença dos acompanhantes um elemento de desgaste ao invés de representar um auxílio na interlocução no trato com a criança.

\section{A precariedade de funcionamento}

Outro obstáculo colocado para a qualidade do trabalho e que acaba por gerar grande tensão diz respeito à falta de material para o hospital. Esse é um tema recorrente nos locais que se destinam a oferecer serviços ao público e nesse hospital, não era diferente, entrecruzando as dificuldades de duas áreas freqüentemente precárias: educação e saúde. Faltam leitos, equipamentos, medicamentos e materiais, além da insuficiência no número de profissionais.

\section{Sentimentos de apatia e sensação de impotência}

Apesar de reconhecerem várias falhas na organização do trabalho, a equipe de enfermagem se queixava de uma impossibilidade de lutar por sua transformação. Esses trabalhadores sentiam-se impotentes para mudar a situação, devido à falta de tempo e falta de compreensão da chefia. Alegavam também que, pelo fato de trabalharem com crianças, estavam impossibilitados de ações mais radicais ${ }^{6}$ na luta por seus interesses. Tínhamos aí uma questão delicada e ao mesmo tempo uma relação de passividade com o trabalho pois atribuíam todas as responsabilidades aos escalóes mais altos da chefia, como se o coletivo de funcionários não fosse responsável por reivindicar, propor mudanças, organizar movimentos, não necessariamente de greve ou de rebelião. Até os seus clientes, as crianças, representavam empecilhos para uma tomada de posição mais positiva em relação ao próprio espaço de trabalho como justificou um elemento do grupo.

Existem vários problemas aqui. É claro que a gente queria lutar por melhorias! Se fosse outro serviço a gente boicotava ou fazia greve. Mas aqui não dá, porque a gente está lidando com a vida de crianças.

\section{Discussão}

Nossas reuniões giraram em torno desses vários assuntos procurando trocar idéias e propor soluções. Alguns resultados talvez possam ser visualizados em longo prazo. Outros já podem ser percebidos, como a conquista de um espaço próprio de discussão dos problemas enfrentados pela equipe.

Conseguir reunir esse grupo, de certa forma, já se constituiu em uma grande vitória. As pessoas trabalhavam de maneira isolada, tomavam decisões individuais, realizavam cada uma a "sua parte" do trabalho. A possibilidade de um espaço para discutir e repensar o trabalho foi muito importante. As respostas vieram prontamente e ficou patente que aquele grupo realmente precisava de mais união e de mais diálogo.

Não há dúvida de que, para conseguir reunir os funcionários, foi preciso um esforço

\footnotetext{
${ }^{6}$ Durante este período houve uma longa greve dos servidores públicos federais, a qual esses funcionários alegavam não poder aderir devido ao fato de cuidarem de crianças.
} 
em conjunto. A chefia se encarregava de mudar os plantões e alterar as folgas. Compareciam, em média, doze funcionários por reunião. Para nós e para o grupo, esse número significava uma vitória, pois pensávamos que seriam colocados muitos obstáculos para inviabilizar a discussão sobre o cotidiano de trabalho. Tudo dava a entender que os trabalhadores estavam naquele lugar apenas para realizar a sua tarefa e nada mais. Não se interessavam pelo que o outro tinha a dizer, não se importavam com o que o chefe queria fazer, e este, por conseguinte, não consultava efetivamente os funcionários antes de tomar decisões importantes. Reunir essas pessoas para discutir esse cotidiano foi, com certeza, uma grande conquista.

O primeiro ponto enfrentado foi justamente a organização da escala de trabalho que gerava uma grande insatisfação para os funcionários e para a chefia, que não sabia como melhorar aquela situação, uma vez que era cobrada por seus superiores para exigir o cumprimento da carga horária completa dos funcionários. A escala representava o momento em que se estabeleciam privilégios, punições, momento este que poderia significar a primazia da racionalidade técnica ou a discussão democrática e o bom senso.

Depois de muita discussão, chegamos a uma decisão de equipe: a escala passou a ser organizada com a participação de um ou dois funcionários para dar sugestões e encaminhar pedidos dos colegas. Dessa forma, controlou-se a distribuição das folgas nos finais de semana, o que foi mais uma conquista. Uma decisão como essa pode parecer simples, mas não foi. Resulta do encontro das pessoas para discutir o cotidiano de trabalho e, consequentemente, fazer modificações para torná-lo mais saudável e menos desgastante.

A saúde de cada um e do grupo também mereceu uma atenção especial. Durante nossos encontros discutimos quais fatores poderiam ser responsáveis por causar mal-estar. $\mathrm{O}$ grupo chegou à conclusão de que, acima de tudo, o que mais incomodava era a falta de união, a dificuldade de formar uma verdadeira equipe apta a discutir os problemas ali presentes e de buscar soluções em conjunto. Os participantes tinham certeza de que isso não era fácil, mas encaravam o desafio, incentivados por nós.

Assim, listamos conjuntamente as providências a serem tomadas para atingir a meta de melhorar o cotidiano de trabalho e a saúde de quem lá trabalha. Foi elaborada uma "receita de saúde" que ficou exposta em um mural de maneira que pudesse envolver outros funcionários. Os "ingredientes" dessa receita dizem respeito, particularmente, à valorização do saber do outro e à socialização das informações e dos espaços de decisão, além de uma atitude propositiva de cobrar soluções concretas para as inúmeras faltas de material e de equipamentos detectadas nesse espaço.

Finalizamos os encontros com o compromisso coletivo de modificar o cotidiano de trabalho, com ênfase na necessidade do empenho de cada um nesta tarefa.

Durante toda a intervenção, os participantes realizaram o exercício de expor suas idéias e ouvir os seus colegas. Prática pouco difundida e para a qual, muitas vezes não se sentiam preparados. Observávamos e percebíamos o que mais os afetava durante a reunião e cuidávamos para que esses assuntos pudessem vir à tona. Foi assim que o grupo formado por funcionários e estudantes de psicologia conseguiu realizar essas importantes conquistas.

Para nós, fica a importância de ter promovido um espaço no local de trabalho em que foi passível discutir os problemas, seus efeitos para a saúde, a necessidade de mudanças de padrões e atitudes cristalizadas. Para o grupo, fica o desafio de continuar tal exercício a cada dia, ouvir o colega, incentivá-lo a falar, buscar estar em seu lugar, compreendendo seu ponto de vista e argumentar na defesa dos seus, de maneira a propiciar que as decisões possam ser tomadas em conjunto. 


\section{Para concluir}

O setor público, particularmente o da saúde, vem passando por um processo de precarização que contribui, sobremaneira, para legitimar que tais serviços devam ser privatizados. Visto sua ineficiência, resta ao cidadão comprar um plano de saúde que lhe ofereça minimamente a segurança de contar com alguma assistência em caso de necessidade. $\mathrm{Na}$ área hospitalar, freqüentemente, explora-se o trabalhador que exerce suas funções, muitas vezes em condições insalubres, com baixos salários e extensas jornadas. Essa política vem funcionando de forma a enfraquecer os sindicatos e dificultar as lutas sociais, contrariando as conquistas de décadas de lutas sindicais. Assim, as gerações de trabalhadores que lutaram durante anos por direitos, como salubridade, redução da jornada de trabalho, salários dignos e segurança, estão vendo suas conquistas serem sufocadas por uma política de desqualificação do setor público e precarização do trabalho.

Frisamos que a precarização do trabalho está ligada a uma precarização da saúde como apontam Vieira e Araujo (2003). Nesse contexto a concepção de saúde, traduz um campo de lutas no qual o sujeito constrói o seu destino, reagindo aos diversos contraintes com os quais é confrontado no cotidiano da vida e particularmente do trabalho.

É importante ressaltar que essa situação descrita é concretizada por meio de práticas que dizem respeito às reformas econômicas, políticas e jurídicas, mas também por meio de discursos que contribuem para a construção de subjetividades individualizadas, homogeneizadas e apáticas, que atendem aos interesses do bloco dominante tomando algumas premissas como verdades incontestáveis.

Assim, podemos refletir que o trabalho produz valores e também os sujeitos que produzem tais valores, ou seja, esse procedimento se desdobra na produção de subjetividades, que por sua vez interferem e transformam o processo de trabalho (Araujo, 2001). Não há dúvidas de que esse interjogo também resulta em padrões de adoecimento ou bem-estar. Um processo dinâmico e aberto às injunções do contexto.

Nesse sentido, o trabalho de intervenção realizado teve como principal objetivo a construção de espaços coletivos e a constituição de sujeitos com capacidade de análise e de intervenção como estratégia para alterar os fatores responsáveis pela produção do adoecimento.

Campos (2000) qualifica esses grupos como grupos de co-gestão, pois trata-se de colocar em análise o trabalho e seus executantes, no sentido de buscar melhores resultados, qualidade no valor de uso produzido - no caso o cuidar - e, ao mesmo tempo, buscar o fortalecimento dos sujeitos, aumentando a capacidade de governo entre todos os membros da equipe e, ainda, avançar na direção de uma maior democracia institucional.

Podemos afirmar que esse grupo visava a alcançar maior autonomia por parte de todos aqueles envolvidos em sua construção. Autonomia, aqui, usada no sentido de aumentar a capacidade de cada um de se expressar e de agir influenciando os demais. Certamente, pudemos perceber que os interesses, muitas vezes, são conflitantes, o que exigiu um grande esforço de argumentação e de compreensão da posição do outro. De qualquer forma, pareceu-nos que esse exercício possibilitou ao grupo de trabalhadores e aos estudantes de psicologia uma maior capacidade de lidar com a vida e de construir instrumentos para lutar cotidianamente pela saúde de si e do grupo. 


\begin{abstract}
Ways to produce health in hospital work: an intervention in Psychology
This paper presents the intervention carried out in a public hospital in Greater Vitória, ES. The purpose of the intervention was to became acquainted with the work reality and its repercussions on the health of the professionals who work in the pediatrics sector of that hospital, aiming at creating a space for reflection and critics in order to promote changes in the working conditions that lead to suffering, as well as in the relationships between the members of the nursing staff. This work used the collective meeting methodology. Using group activities, varied texts and resources, it dealt with several subjects concerning the work reality and the possible consequences for the health and life of those men and women. It was observed that the working conditions and the organization in the sector have favored illness as a result of a process of disqualification and impoverishment of the public health service. The work brought up collective efforts to face problems and seek solutions for them. However, it stands out that much has yet to be done in order to accomplish other co-management experiences and find solutions for the innumerable problems in the work routine of the hospital.
\end{abstract}

Keywords: hospital work, work psychology, health and work, psychology intervention.

Endereço para contato com as autoras: dalbello@intervip.com.br

Manuscrito recebido em: 16/11/2001

Envio de pareceres às autoras em: 27/02/2002

Novo manuscrito recebido em: 02/10/2002

Envio de pareceres às autoras em: 29/11/2002

Aprovado para publicação em: 20/12/2002

\title{
Referências bibliográficas
}

Araujo, M. D. (2001). Psicologia social, trabalho e contemporaneidade: o trabalho portuário e suas vicissitudes. In H. Novo, L. Souza e A. N. Andrade (Orgs.), Ética, cidadania e participação: debates no campo da Psicologia (pp. 191-211). Vitória: Edufes, CCHN Publicações.

Birman, J. (1999). Os sentidos da Saúde. Revista de Saúde Coletiva, 9 (1), 7-13.

Braverman, H. (1981). Trabalho e capital monopolista: a degradação do trabalho no século XX. Rio de Janeiro: Guanabara.

Campos, G. W. S. (2000). O método da roda: um método para análise e co-gestão de coletivos. São Paulo: Hucitec.

Canguilhem, G. (1978). O Normal e o patológico. Rio de Janeiro: Forense Universitária.

Caponi, S. (1997). Georges Canguilhem y el estatuto epistemológico del concepto de salud. História, Ciências, Saúde, 4, 287-307.

Dejours, C. (1986). Por um novo conceito de saúde. Revista Brasileira de Saúde Ocupacional. 14 (54), 7 11.

Dejours, C. (1987). A Loucura do trabalho. São Paulo: Cortez-Oboré.

Dejours, C. \& Abdoucheli, E. (1994). Itinerário teórico em psicopatologia do trabalho. In C. Dejours, E. Abdoucheli \& C. Jayet (Orgs.), Psicodinâmica do Trabalho: contribuições da escola dejouriana à análise da relação prazer, sofrimento e trabalho. São Paulo: Atlas. 
Dejours, C, Dessors, D. \& Desriaux, F. (1993). Por um trabalho fator de equilíbrio. Revista de Administração de Empresas, 33 (3), 98-104.

Foucault, M. (1979). Microfísica do poder. Rio de Janeiro: Graal.

Lima, M. J. (1993). O que é enfermagem? São Paulo: Brasiliense.

Mello Neto, J. C. (1994). Morte e vida Severina. Rio de Janeiro: Nova Fronteira.

Pitta, A. (1999). Hospital: dor e morte como ofício. São Paulo: Hucitec.

Rigotto, R. M. (1994). O homem e o trabalho. In J. T. Buschinelli, L. Rocha \& R. M. Rigotto (Orgs.), Isto é trabalho de gente? Petrópolis: Vozes.

Vieira, S. B. \& Araujo, A. J. S. (2003) Genêro, precarização e saúde no trabalho hospitalar. In M. D. P. Carvalho \& M. Z. C. Pereira (Orgs.), Gênero e Educação: Múltiplas Faces. João Pessoa: Editora da UFPb. 